\title{
Zoonotic Transmission and Host Switches of Malaria Parasites
}

\author{
Xin-zhuan Su* and Jian Wu
}

\begin{abstract}
Malaria is a deadly disease that affects the health of hundreds of millions of people annually. Five Plasmodium parasite species naturally infect humans: Plasmodium falciparum, Plasmodium vivax, Plasmodium malariae, Plasmodium ovale, and Plasmodium knowlesi. These parasites can also infect various nonhuman primates. Parasites mainly infecting monkeys, such as Plasmodium cynomolgi and $P$. knowlesi, the latter of which was considered to be a monkey parasite for years, can also be transmitted to human hosts. Recently, many new Plasmodium species have been discovered in African apes, some of which may be transmitted to humans in the future. Here, we searched PubMed and the internet via Google and selected articles on the zoonotic transmission and evolution of selected malaria parasite species. We review current advances in the relevant topics, emphasizing the transmission of malaria parasites between humans and non-human primates. We also briefly discuss the transmission of some avian malaria parasites between wild birds and domestic fowls. Zoonotic malaria transmission is widespread, thus posing a threat to public health. More studies on parasite species, including their identification in non-human primates, transmission, and evolution, are needed to decrease or prevent the transmission of malaria parasites from non-human primates to humans.
\end{abstract}

Key words: Plasmodium, non-human primate, outbreak, simian, ape, avian

\section{INTRODUCTION: MALARIA PARASITES AND LIFE CYCLES}

Malaria remains a serious public health burden worldwide: approximately 229 million clinical cases and 368,000 deaths were reported in 87 malaria endemic countries in 2019 [1]. Nearly 300 Plasmodium species have been characterized, infecting mammals, rodents, birds, lizards, bats, and ungulates; at least 29 species have been found to infect non-human primates [2-4] (https://en.wikipedia.org/wiki/ List_of_Plasmodium_species). Human malaria is caused by five Plasmodium species: Plasmodium falciparum, Plasmodium vivax, Plasmodium malariae, Plasmodium ovale, and Plasmodium knowlesi. P. falciparum is the deadliest, whereas $P$. vivax is the most widespread. Malaria parasites infecting a group of related vertebrate species generally have relatively strict host specificity. Plasmodium berghei, Plasmodium chabaudi, and Plasmodium yoelii, initially isolated from African thicket rats, infect only rodent hosts, such as mice and rats; in contrast, Plasmodium gallinaceum and Plasmodium relictum infect avian hosts [5,6]. The rodent or avian parasites do not infect humans and do not pose a threat to public health. However, they may have economic impacts; avian parasites infecting wild birds
Edited by:

Wei Wang, Jiangsu Institute of

Parasitic Diseases, China

Reviewed by:

Jian Li, Hubei University of Medicine, China

Another reviewer chose to be anonymous

*Corresponding author:

E-mail: xsu@niaid.nih.gov

Malaria Functional Genomics Section, Laboratory of Malaria and Vector Research, National Institute of Allergy and Infectious Disease, National Institutes of Health, Bethesda, MD 20892-8132, USA

Received: September 282021 Revised: October 112021 Accepted: October 122021

Published Online: November 22021 
may be transmitted to domestic fowls and kill host animals kept in zoos or raised for food $[7,8]$.

Many Plasmodium species can be transmitted between humans and non-human primates. For example, human infections of the New World monkey parasites Plasmodium simium and Plasmodium brasilianum have been widely reported [9]. P. simium is closely associated with P. vivax, and P. brasilianum is almost identical to P. malariae, thus suggesting transmission of these parasites between humans and New World monkeys. Recently, many potential new Plasmodium species were discovered in African apes [10-15]. Whether these parasites might infect humans, either currently or in the future, remains to be determined. Human activities expanding deeper into jungles, together with the continuing evolution of Plasmodium parasites, increases the likelihood of non-human primate parasites jumping to humans. Threats of infection of humans or domestic animals by parasites in wild animals still exist, and additional investigation on parasite evolution, adaptation, and prevention of cross-species transmission is needed.

Malaria parasites have a complex life cycle involving two hosts: female mosquitoes (Anopheles for most malaria parasites) and humans or other vertebrates as secondary hosts (Fig 1). The life cycle starts with a bite from an infected mosquito, which injects sporozoites into the skin of a vertebrate host. The sporozoites migrate within blood vesicles to the liver and infect hepatocytes $[16,17]$. A parasite can replicate into thousands of merozoites inside a hepatocyte, and mature merozoites are released into the bloodstream and subsequently invade erythrocytes after rupture of infected hepatocytes. Within a red blood cell (RBC), a merozoite replicates again and develops from ring to trophozoite and schizont stages. The rupture of RBCs containing schizonts also releases metabolic by-products including hemozoin from parasite digestion of hemoglobin. The parasite products trigger host immune responses and cause various clinical symptoms such as fever, chills, myalgia, headache, dizziness, and back pain [18]. For some patients, the infection may progress to severe malaria with coma (cerebral malaria), pulmonary edema, acidosis, hypoglycemia, acute renal failure, jaundice, severe anemia, and death [19-21]. Host responses, such as the release of metabolites and immune effectors, may also trigger some parasites to differentiate into male and female gametocytes [22,23]. When another mosquito consumes a bloodmeal from an infected host, the gametocytes differentiate into male and female gametes that fertilize to form zygotes in the midgut. The zygotes then develop into motile ookinetes that penetrate the mosquito midgut wall and develop into oocysts. A mature oocyst contains thousands of sporozoites that migrate to salivary glands. When a mosquito bites a vertebrate host, sporozoites are injected into the skin, and a life cycle begins. All Plasmodium species have

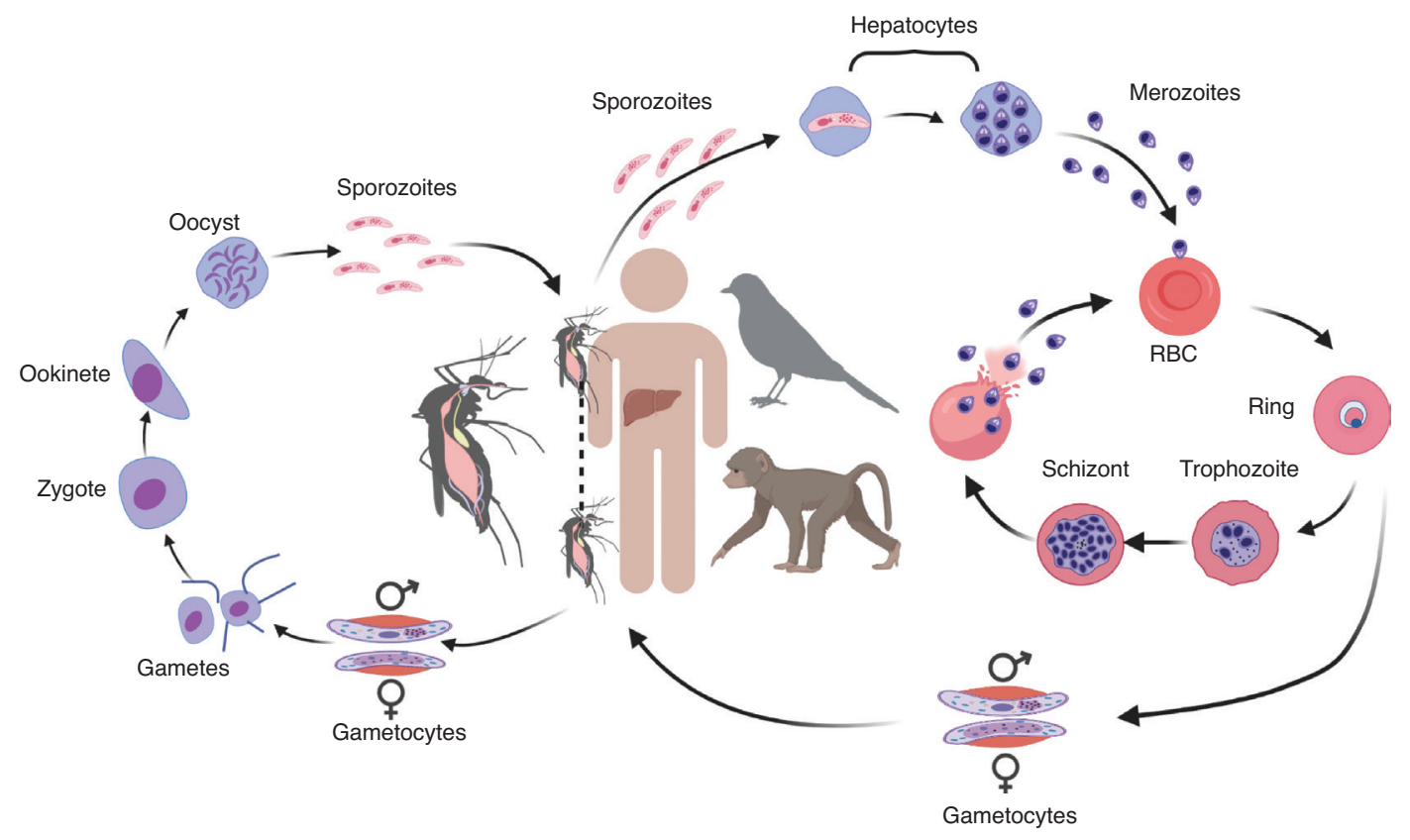

FIGURE 1 | Representative life cycle of malaria parasites. Injection of sporozoites into a vertebrate host by a mosquito bite initiates the infection and the parasite life cycle. The injected sporozoites travel through the bloodstream to the liver and invade hepatocytes, where the parasites replicate and produce thousands of merozoites. Mature merozoites are again released into the bloodstream, where they invade red blood cells (RBCs). Within an RBC, the parasite replicates, producing more merozoites that can invade new RBCs for another cycle. For unknown reasons, some merozoites may develop into male and female gametocytes that differentiate into male and female gametes in the mosquito midgut when another a mosquito takes a blood meal. The male and female gametes fertilize, forming zygotes that differentiate into motile ookinetes. The ookinetes penetrate the mosquito midgut and develop into oocysts outside the midgut wall. Each oocyst contains many sporozoites that travel to the mosquito salivary glands. When the mosquito bites another vertebrate host, the sporozoites are injected into the new host, thus starting another cycle. 
similar life cycles with different species of mosquito and vertebrate hosts, although the life cycle length can differ. For example, the erythrocytic cycle is approximately $24 \mathrm{~h}$ for P. knowlesi; 48 h for P. falciparum, P. vivax, and P. ovale; and 72 h for P. malariae [19,24-27].

For this brief review, we searched PubMed and Google for selected parasite species (including $P$. falciparum, $P$. vivax, P. malariae, P. ovale, P. knowlesi, P. cynomolgi, P. simium, and P. brasilianum), together with phrases such as 'zoonotic transmission', 'molecular evolution', 'host switch', and 'monkey or non-human primate malaria'. Selected relevant references cited in published articles were also reviewed and are discussed. The following section briefly describes the origins and zoonotic transmission of important malaria parasites that infect humans and non-human primates, as summarized in Fig 2. Examples of avian malaria parasites causing damage to birds in zoos and to domestic fowls are also briefly discussed.

\section{THE ORIGIN OF P. FALCIPARUM AND ITS TRANSMISSION BETWEEN HUMANS AND APES}

With the development of DNA sequencing and genotyping tools, the origins and evolutionary histories of malaria parasites have become topics of interest, and debates are ongoing regarding the origins and times of divergence from the common ancestors of $P$. falciparum and $P$. vivax [28,29]. Analysis of small-subunit ribosomal RNA genes initially suggested that P. falciparum and avian parasites share

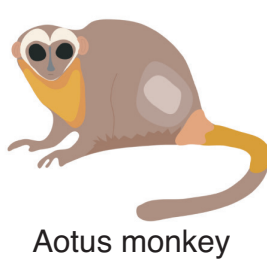

Aotus monkey

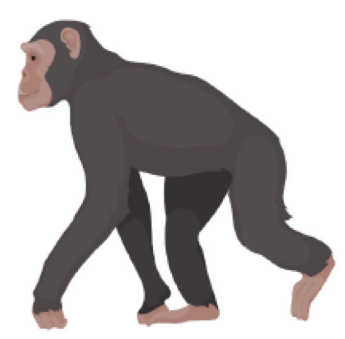

Chimpamzee

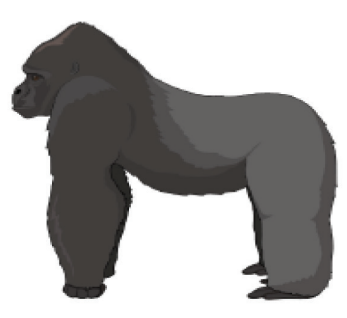

Gorrilas

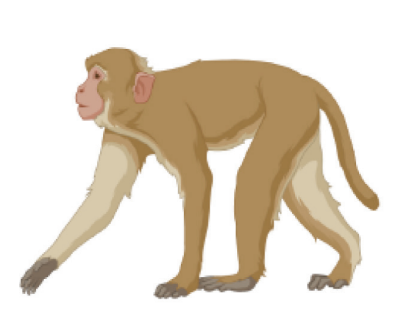

Rhesus macaque

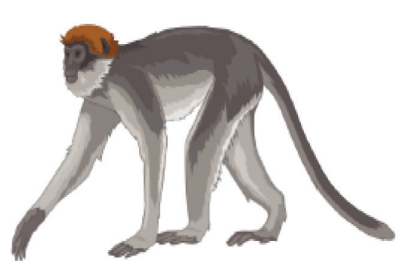

Asian monkey
P. vivax

P. cynomolgi

P. knowlesi
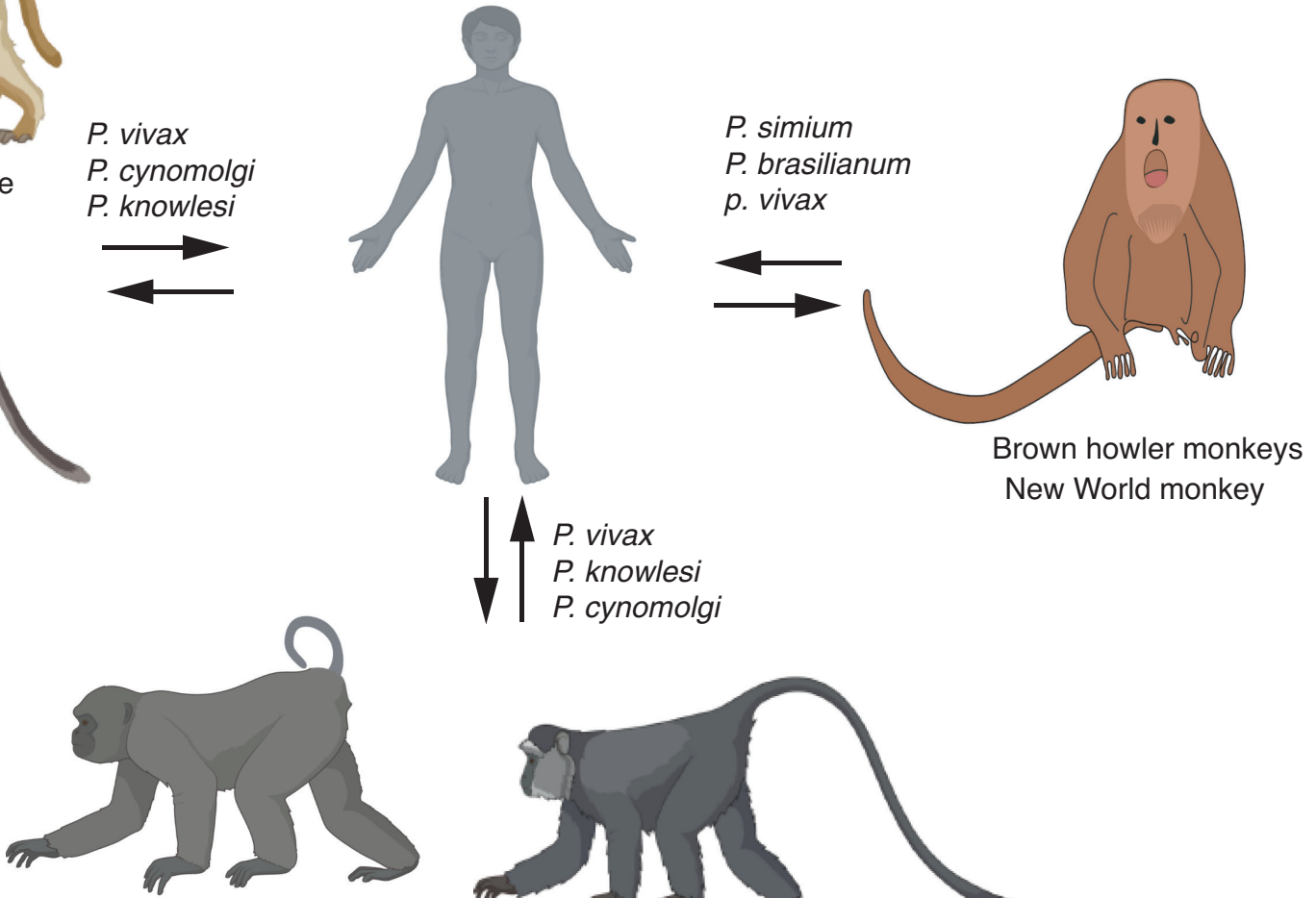

Pig-tailed macaques

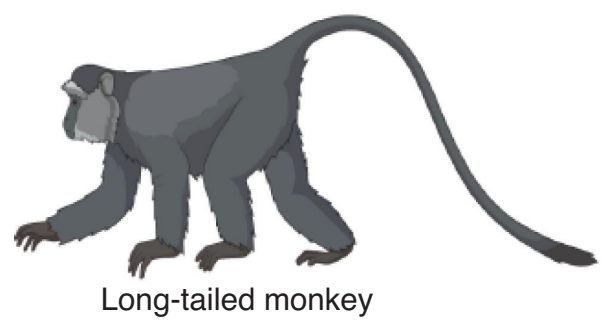

$\downarrow \begin{aligned} & \text { P. falciparum and } \\ & \text { Laverania species } \\ & P . \text { vivax }\end{aligned}$

Saimiri monkey

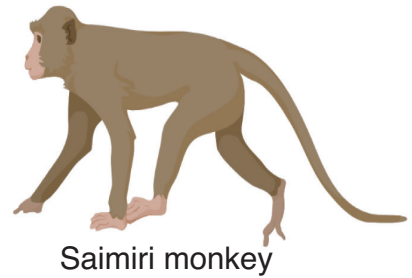

New World monkey

FIGURE 2 | Potential transmission of malaria parasites between humans and non-human primates. Arrows indicate the direction of potential transmission of malaria parasites. The cartoons of non-human primates were created with Biorender (https://biorender.com) for illustration purposes only; they might not accurately reflect the characteristics of the species. 
a relatively recent progenitor [30]. The chimpanzee parasite Plasmodium reichenowi has long been considered the closest species to P. falciparum, because both parasites have high-AT content genomes and share a high degree of genome similarity [31]. According to one longstanding hypothesis, $P$. falciparum and P. reichenowi evolved from a $P$. falciparum-like common ancestor, then co-evolved with their respective hosts for millions of years [32]. Recent discoveries of a multitude of Plasmodium spp. in chimpanzees and gorillas suggest that $P$. falciparum probably arose from recent cross-species transmission of parasites from African apes [14,15,29,33,34]. In one study, DNA sequences in nearly 3,000 fecal samples collected from wild-living apes (chimpanzees and gorillas) were amplified and sequenced [14]. Analysis of more than 1,100 mitochondrial, apicoplast, and nuclear gene sequences from the animals grouped most of the sequences within one of six chimpanzee- or gorilla-specific lineages representing distinct Plasmodium species, including three not previously reported. Nine sequences were also associated with another group of human parasites with higher GC content (P. malariae, $P$. ovale, or $P$. vivax). These studies indicated the presence of many Plasmodium species belonging to the Laverania subgenus in the apes: P. gaboni, P. billcollinsi, and $P$ reichenowi in chimpanzees; and $P$. praefalciparum, $P$. blackloci, and P. adleri in gorillas [14,35]. Additionally, Plasmodium lomamiensis was later identified in bonobos [15]. P. falciparum is also a member of the Laverania group and is the only parasite that has successfully adapted to humans after a potential transfer from gorillas to humans [14,35]. P. falciparum has been proposed to have arisen from a single transfer of $P$. praefalciparum into humans [36]. Indeed, P. falciparum is closely associated with $P$. praefalciparum, with an estimated divergence time of 40,000-60,000 years, and signals have indicated significant gene flow between these two parasite species after their initial divergence [35]. The jump of parasites from African apes to humans was probably due to adaption and mutations in a limited number of parasite genes involved in the invasion of RBCs and host-parasite interactions $[35,37]$. Parasites infecting different primate hosts appear to have various genes that are involved in either invasion or pathogenesis and have been fixed in the genomes [35]. For example, the interaction of the P. falciparum ligand EBA-175 with its erythrocyte sialoglycoprotein receptor, glycophorin A (GPA), plays a role in parasite invasion of RBCs [38]. Ape GPA sialic acid residues contain predominantly $\mathrm{N}$-glycolylneuraminic acid (Neu5Gc), whereas those of humans have $\mathrm{N}$-aceytlneuraminic acid (Neu5Ac). The difference in Neu5Ac and Neu5Gc determines the receptor-ligand specificity: P. falciparum EBA-175 cannot bind chimpanzee GPA, whereas the P. reichenowi homolog of EBA-175 cannot bind human GPA [39].

Although P. falciparum is known to naturally infect only humans, several splenectomized non-human primates have been shown to support $P$. falciparum growth and have been explored as animal models for studies of vaccine development and genetic crosses. Aotus infulatus (owl) monkeys, both intact and splenectomized, can be infected with
P. falciparum [40,41]. Animals with intact spleens have low parasitemia but develop complications such as severe anemia, whereas splenectomized monkeys have substantial parasitemia without major complications. Similarly, spleen-intact and splenectomized saimiri monkeys can also be infected with the Indochina 1/CDC and Uganda Palo FUP strains of $P$. falciparum; however, the animals recover without developing severe disease [42]. Additionally, P. falciparum strains can be adapted to grow in splenectomized chimpanzees, which have been used as hosts for genetic crosses [43-45]. The parasites in the apes are changing and evolving, and additional parasites might potentially jump from African apes to humans, thus resulting in new human malaria parasite species in the future.

\section{THE ORIGIN OF $P$. VIVAX AND ITS TRANSMISSION BETWEEN HUMANS AND NON-HUMAN PRIMATES}

P. vivax is another important human malaria parasite that is endemic to Asia, Oceania, and Central/South America, but is rare in sub-Saharan Africa because of the absence of Duffy antigen on the RBCs in human populations in Africa [46]. The ongoing debate concerning the origin of $P$. vivax is interesting, given that data support both Asian and African origins. Several earlier studies have suggested that $P$. vivax might have arisen from the cross-species transmission of parasites between humans and macaques in Southeast Asia [47-50]. However, the hypothesis of Asian origin has recently been challenged after the characterization of many additional Plasmodium parasites from African apes [29]. Additional sequences from wild chimpanzees and gorillas throughout central Africa have shown that these animals were endemically infected with parasites closely associated with $P$. vivax, thus suggesting that $P$. vivax might have emerged in Africa [51]. Phylogenetic relationships derived from apicoplast genome sequences of several Asian primate parasites, Plasmodium cynomolgi, P. knowlesi, Plasmodium fragile, Plasmodium fieldi, Plasmodium simiovale, Plasmodium hylobati, Plasmodium inui, and P. gonderi also support an African origin of $P$. vivax [52]. However, recent analyses of genomic variation in 447 human $P$. vivax strains and 19 ape $P$. vivaxlike strains collected worldwide have indicated that $P$. vivax might have arisen from a single area in Asia through serial founder effects [53]. P. vivax has been shown to be a sister group rather than a sublineage of $P$. vivax-like parasites, and a strong bottleneck in the lineage leading to $P$. vivax may explain the richer genetic diversity in the P. vivax-like groups [53]. Notably, before these recent analyses of large numbers of parasite isolates and genomic datasets, Richard Carter provided some potential answers to the debates on P. vivax origin, on the basis of changes in historical continental landmasses, climate, the distribution of primates over time, and malaria parasite selection on the human genome (Duffy negative) in the Old World [54,55]. Carter has speculated that $P$. vivax could have diverged $\sim 2$ million years ago from a group of malaria parasites that are now endemic in 
monkeys and apes in southern Asia, and all P. vivax today might be descended from parasites that infected human populations in the Mediterranean region and sub-Saharan Africa [55]. This hypothesis might explain the discrepant signals found in parasite sequences collected from Asian and Africa. Nonetheless, although the debate on the origin of $P$. vivax is expected to continue, these studies clearly illustrate the zoonotic nature of P. falciparum and P. vivax parasites.

\section{EMERGENCE OF $P$. VIVAX IN AFRICA AND THE INVASION OF DUFFY NEGATIVE RBCS}

An African origin of P. vivax is supported by the lack of Duffy antigen expression in African human populations and the requirement of Duffy antigen/chemokine receptor (DARC) for parasite invasion of RBCs [46,55]. The P. vivax parasite invades reticulocytes mainly through binding of P. vivax Duffy binding protein (PvDBP) to DARC [56-58]. For many years, Duffy-negative individuals were thought to be fully resistant to vivax malaria, as an example of selection of a genetic trait by an infectious disease [59]. An amino acid substitution in the GATA-1 transcription factor binding site of the gene encoding the Duffy blood group, $F Y$, causes an absence of DARC expression [60]. However, P. vivax has since been reported in Duffy-negative human populations [61-66]. Duplication of the PvDBP genes and low-level expression of the gene (which was previously undetectable) encoding DARC (Fy) might have contributed to the observations of $P$. vivax in Duffy-negative individuals [67-71]. Additionally, African great apes may act as Duffy-positive reservoirs of $P$. vivax in regions where $P$. vivax parasites (or P. vivax-like parasites) have been found in the blood of these great apes [72,73]. These observations show that new infections may occur after mutations in both host and parasite genomes, thereby leading to new transmission. However, no significant difference in PvDBP copy number has been observed in parasites infecting Duffy-null heterozygotes and Duffy-positive homozygotes/heterozygotes [74]. The molecular mechanism of infection in Duffy-negative individuals requires further investigation.

\section{P. VIVAX/P. SIMIUM IN HUMANS AND NEW WORLD MONKEYS}

P. simium can infect neotropical platyrrhine monkeys and humans. Although how P. simium specifically arrived in the Americas remains disputed, most scientists studying the parasite agree that $P$. simium was established in New World monkeys after migrants brought the parasite (or P. vivax initially) either from Europe and Africa during the colonial era, or from Southeast Asia [75,76]. P. vivax and P. simium have nearly identical genomes, and parasites found in humans and simians can be transmitted by the same vectors in the Atlantic Forest of Brazil [77]. More recent phylogenetic analyses based on the whole genome sequences of $P$. simium isolates infecting humans and brown howler monkeys support the hypothesis that $P$. simium first infected non-human primates as a result of a host-switch from humans carrying P. vivax $[78,79]$. Additionally, signals of multiple independent host switches have been detected, thus suggesting that zoonotic infections occurred in humans, and non-human primate malaria parasites serve as reservoirs for potential human infectious [79]. Indeed, an outbreak of P. simium malaria in humans in the Atlantic Forest in Rio de Janeiro has been reported [80]. Transmission from non-human primates to humans must be considered in any malaria elimination attempts in the region.

\section{P. OVALE AND POTENTIAL ZOONOTIC TRANSMISSION}

P. ovale is a human malaria parasite producing oval shaped infected erythrocytes $[25,81]$. Similarly to $P$. vivax, the parasites invade primarily reticulocytes to initiate the erythrocytic cycle, and they can suspend their development as hypnozoites in the liver for months, thus leading to relapses [25]. The parasite is found mostly in sub-Saharan Africa; islands of the western Pacific, such as the Philippines and New Guinea; the Middle East; and Southeast Asia [82-90]. Recently, two nonrecombining species of P. ovale, P. ovale curtisi (classic type) and P. ovale wallikeri (variant type), have been recognized [91,92]. Phylogenetic analysis of the Plasmodium genus on the basis of genomic sequences has placed $P$. ovale curtisi and $P$. ovale wallikeri in a clade between those of P. vivax/P. cynomolgi and P. berghei/P. chabaudi [93]. The study also supports relatively ancient divergence of the two P. ovale species, as evidenced by their different pir repertoires [93].

Genetic evidence has indicated the presence of $P$. ovale parasites in African chimpanzees. In a study of partial mitochondrial cytochrome b (cytb) and cytochrome coxidase 1 (cox1) and nuclear $l d h$ sequences from 130 samples collected from chimpanzees (Pan troglodytes) and gorillas (Gorilla gorilla) in Cameroon, $P$. olave sequences were detected in two chimpanzees [90]. One chimpanzee was infected with parasites whose sequences were identical to those of the variant ( wallikeri) P. ovale type, and the other was infected with parasites different from the two human $P$. ovale parasites. In a similar study, blood samples from 12 chimpanzees and two gorillas from Cameroon and one lemur from Madagascar were examined for two parasite mitochondrial genes $(c y t b$ and $\operatorname{cox} 1)$, one plastid gene $(\operatorname{tuf} A)$, and $l d h ; P$ ovale was found in the chimpanzees [94]. In another study, 16 wild West African chimpanzees in Taï National Park, Côte d'Ivoire, were found to be naturally infected with $P$. ovale, P. vivax, $P$. malariae, and three types of plasmodia rarely observed in humans in the region [95]. These observations suggest potential natural cross-species exchange in $P$. ovale between humans and chimpanzees.

\section{HUMAN INFECTION OF P. MALARIAE AND P. BRASILIANUM}

Simian P. brasilianum causes quartan fever in New World monkeys and resembles the human quartan parasite 
P. malariae under microscopic examination. P. brasilianum parasites from monkeys have been found to infect humans experimentally, and New World monkeys or chimpanzees can be experimentally infected with $P$. malariae from humans [96-99]. The two parasites are nearly genetically identical $[9,93,100,101]$. Typically, quartan malaria parasites were called $P$. brasilianum when identified in monkeys and P. malariae when detected in humans [101]. Analyses of parasite genes encoding the circumsporozoite protein (CSP) and the ribosomal small subunit (18S) from patients in remote Yanomami indigenous communities in Venezuela have identified 12 people harboring parasites $100 \%$ identical to P. brasilianum isolated from the monkeys, thus suggesting naturally acquired human infections of $P$. brasilianum [101]. Monkeys living in the rainforest therefore can act as natural reservoirs for P. brasilianum/P. malariae malaria [100]. Some studies have shown that $P$. brasilianum strains appear to be more divergent than $P$. malariae parasites $[9,102]$, thereby suggesting that $P$. malariae might be derived from $P$. brasilianum. However, the level of genetic variation was minimal, and the diversity could represent intraspecies variation.

Genome sequence and phylogenetic analyses have shown that $P$. malariae and P. malariae-like make up a clade at the root of clades consisting of P. vivax/knowlesi/cynomolgi, P. ovale, and P. berghei/chabaudi [93]. Additionally, the cytb and $s s r R N A$ sequences of $P$. malariae and P. malariae-like have been found in wild chimpanzees in tropical Africa [14,95], thus suggesting potential transmission of $P$. malariae or P. malariae-like parasites from chimpanzees to humans.

\section{OUTBREAKS OF P. KNOWLESI INFECTIONS IN HUMAN POPULATIONS}

P. knowlesi is a malaria parasite initially found in longtailed (Macaca fascicularis) and pig-tailed (Macaca nemestrina) macaques, and human infections were thought to be rare until natural infections in many human individuals were reported in Sarawak, Malaysian Borneo, in 2004 [103,104]. The parasite was first observed in blood film from a longtailed macaque in the early 1930s [103]. Subsequently, blood passage of the parasite in its natural host, M. fascicularis, was found to result in infection with low parasitemia [103]. Human natural infection was reported in a U.S. Army surveyor in Peninsular Malaysia more than 30 years later [105]. However, many human infections of $P$. knowlesi were likely to be misdiagnosed as $P$. malariae infections in routine microscopy, because the blood stages of $P$. knowlesi and P. malariae are morphologically very similar [106]. More extensive human infections of $P$. knowlesi have been discovered in the past 15 years, particularly with the development and application of PCR-based techniques, which have greatly improved the ability to detect $P$. knowlesi infection in humans and monkeys [104]. After the report of a large focus of human infections of $P$. knowlesi in Malaysian Borneo in 2004 [107,108], human cases of P. knowlesi infections have been reported in Malaysia [109-111] Thailand [112-114], Cambodia [115,116], Vietnam [117], Myanmar
[118], the Philippines [119], Singapore [120,121], and Indonesia [122]. Importantly, the areas with natural human $P$. knowlesi infections overlap with the distribution of longtailed and/or pig-tail macaques. Therefore, P. knowlesi is now recognized as the fifth human malaria species, and zoonotic transmission plays a key role in human infections. The zoonotic transmission of $P$. knowlesi represents a challenge for malaria control and elimination in Southeast Asia [123]. Indeed, zoonotic P. knowlesi infection has become the major cause of malaria in Malaysia, particularly Malaysian Borneo [124].

\section{HUMAN INFECTIONS WITH THE MONKEY MALARIA PARASITE P. CYNOMOLGI}

P. cynomolgi is another malaria parasite that naturally infects Asian monkey species, including long-tailed and pig-tailed macaques [125]; however, this parasite may also occasionally infect humans [126]. Human infection has been reported in two staff members who became infected with vivax-type parasites when they inoculated monkeys with P. cynomolgi sporozoites [127]. Additional transmission of P. cynomolgi from monkeys to humans or from among humans was reported shortly thereafter [128-131]. Naturally acquired human infection of P. cynomolgi was reported in a symptomatic 39-year-old female nurse in peninsular Malaysia in 2014 [132]. In a more recent survey of malaria infections involving 14,732 individuals in 23 villages in Pailin and Battambang, western Cambodia, 1,361 people were asymptomatically infected with several species of malaria parasites, including 11 people infected with P. cynomolgi, 8 people infected with $P$. knowlesi, and 2 people infected with both P. vivax and P. cynomolgi [116]. In Northern Sabah, Malaysia, two adult men were found to be infected with P. cynomolgi [110]. Additionally, 6 of 1,047 blood samples collected at Kapit Hospital in Kapit, Malaysia, were found to be co-infected with P. cynomolgi and P. knowlesi [111]. These reports suggest that $P$. cynomolgi can also infect humans naturally, although the prevalence of $P$. cynomolgi infection in humans may be lower than that of $P$. knowlesi. More outbreaks of $P$. cynomolgi infection might potentially be undetected or could occur in the future if the parasites acquire mutations in the key parasite genes involved in binding to host receptors.

\section{MALARIA SPECIES IN BIRDS AND THEIR TRANSMISSION BETWEEN CAPTIVE/ DOMESTIC AND WILD BIRDS}

Avian hosts are infected with many species of malaria parasites such as $P$. relictum, Plasmodium elongatum, Plasmodium juxtanucleare, and P. gallinaceum [6,133]. Although these parasites do not infect humans and are generally not of concern to public health, transmission of parasites from wild birds to domestic fowls can inflict economic losses on the poultry industry. Transmission of many avian malaria species is mediated by species of Culicidae mosquitoes in several 
genera (Culex, Coquillettidia, Aedes, Mansonia, Culisetta, Anopheles, and Psorophora), instead of the Anopheles species for mammalian malaria parasites $[134,135]$. Many species of avian malaria parasites exist among wild birds, but studies on the disease severity and pathology in wild birds are limited [136,137]. Traditionally, wild birds infected with these parasites were generally considered to have mild disease. However, avian malaria has been shown to play a role in the ongoing decline of native New Zealand birds [138]. Diminished overwinter survival of both juvenile and adult house sparrows has been associated with the intensity of Plasmodium infections [139]. Various clinical signs have been observed in domestic chickens after infection with P. gallinaceum, including depression, fever, anorexia, reduced weight gain, poor feed conversion, anemia, green feces, and even death [140]. Death of experimental passerine birds due to marked organ damage has been reported after Plasmodium homocircumflexum infection [137]. Avian malaria, most commonly associated with $P$. relictum or $P$. elongatum, can also cause severe disease in penguins, with mortality rates as high as $50 \%-80 \%$ [141]. Vector and bird migration and vector introduction by human action into non-endemic habitats represents a risk of endangering species [142]. For example, P. relictum has recently been reported to expand its range, infecting two non-migratory passerines in North America [143]. Species of Plasmodium, Haemoproteus, and Leucocytozoon have been reported to infect cranes in the Beijing Zoo, particularly the juvenile birds that often die from infection by Plasmodium and Leucocytozoon parasites [144]. Therefore, the transmission of avian malaria parasites between wild birds and domestic or captive avian hosts can be considered examples of zoonotic transmission of malaria parasites.

\section{CONCLUSION}

The transmission of malaria parasites from non-human primates to humans and vice versa has occurred many times during the evolutionary histories of malaria parasites and their hosts. Moreover, some parasites have adapted to develop in both humans and non-human primates. All five malaria parasite species that infect humans have been found in non-human primates, which in turn can act as reservoirs for transmission to humans. Additionally, the malaria species currently infecting wild non-human primates may gain mutations that allow them to bind receptors in humans and subsequently jump to humans. Furthermore, many unknown species in wildlife hosts remain to be characterized. One approach might be to collect fecal or tissue (blood) samples from potential hosts such as bats, wild rodents, and non-human primates, and extract DNA/RNA for high throughput sequencing to reveal parasite genetic information for species characterization.

The risk of malaria parasite outbreaks is a frequent threat to public health when human activities lead to close contact with non-human primates. Close surveillance and more studies on the biology and transmission of parasites circulating among non-human primates are of critical importance for preventing outbreaks of malaria due to zoonotic infection.

\section{ACKNOWLEDGEMENTS}

This work was supported by the Division of Intramural Research, National Institute of Allergy and Infectious Diseases (NIAID), National Institutes of Health $(\mathrm{NIH})$, USA.

The authors thank Ms. Christine Caufield-Noll, NIH Library Editing Service, for manuscript editing assistance.

\section{CONFLICTS OF INTEREST}

The authors declare no competing interests.

\section{REFERENCES}

1. WHO. World malaria report 2020; 2020. https://wwwwhoint/ publications/i/item/9789240015791.

2. Schall JJ. Lizards infected with malaria: physiological and behavioral consequences. Science. 1982;217(4564):1057-1059.

3. Schaer J, Perkins SL, Decher J, Leendertz FH, Fahr J, Weber N, et al. High diversity of West African bat malaria parasites and a tight link with rodent Plasmodium taxa. Proc Natl Acad Sci U S A. 2013;110(43):17415-17419.

4. Templeton TJ, Asada M, Jiratanh M, Ishikawa SA, Tiawsirisup $\mathrm{S}$, Sivakumar T, et al. Ungulate malaria parasites. Sci Rep. 2016;6:23230.

5. Ramiro RS, Reece SE, Obbard DJ. Molecular evolution and phylogenetics of rodent malaria parasites. BMC Evol Biol. 2012;12:219.

6. Fecchio A, Chagas CRF, Bell JA, Kirchgatter K. Evolutionary ecology, taxonomy, and systematics of avian malaria and related parasites. Acta Trop. 2020;204:105364.

7. Grim KC, van der Merwe E, Sullivan M, Parsons N, McCutchan TF, Cranfield M, et al. Plasmodium Juxtanucleare associated with mortality in black-footed penguins (Spheniscus demersus) admitted to a rehabilitation center. J Zoo Wildl Med. 2003;34(3):250-255.

8. Grim KC, McCutchan T, Sullivan M, Cranfield MR. Unidentified Plasmodium species in Australian black swans (Cygnus atratus) hatched and raised in North America. J Zoo Wildl Med. 2008;39(2):216-220.

9. Tazi L, Ayala FJ. Unresolved direction of host transfer of Plasmodium vivax v. P. simium and P. malariae v. P. brasilianum. Infect Genet Evol. 2011;11(1):209-221.

10. Ollomo B, Durand P, Prugnolle F, Douzery E, Arnathau C, Nkoghe $D$, et al. A new malaria agent in African Hominids. PLoS Pathogens. 2009;5(5):e1000446.

11. Prugnolle F, Durand P, Neel C, Ollomo B, Ayala FJ, Arnathau C, et al. African great apes are natural hosts of multiple related malaria species, including Plasmodium falciparum. Proc Natl Acad Sci U S A. 2010;107(4):1458-1463.

12. Krief S, Escalante AA, Pacheco MA, Mugisha L, André C, Halbwax M, et al. On the diversity of malaria parasites in African Apes and the origin of Plasmodium falciparum from bonobos. PLoS Pathog. 2010;6(2):e1000765.

13. Duval L, Ariey F. Ape Plasmodium parasites as a source of human outbreaks. Clin Microbiol Infect. 2012;18(6):528-532.

14. Liu W, Li Y, Learn GH, Rudicell RS, Robertson JD, Keele BF, et al. Origin of the human malaria parasite Plasmodium falciparum in gorillas. Nature. 2010;467(7314):420-425.

15. Liu W, Sherrill-Mix S, Learn GH, Scully EJ, Li Y, Avitto AN, et al. Wild bonobos host geographically restricted malaria parasites including a putative new Laverania species. Nat Commun. 2017;8(1):1635.

16. Baer K, Roosevelt M, Clarkson AB, Jr., van Rooijen N, Schnieder T, Frevert U. Kupffer cells are obligatory for Plasmodium 
yoelii sporozoite infection of the liver. Cell Microbiol. 2007;9(2):397-412.

17. Tavares J, Formaglio P, Thiberge S, Mordelet E, van Rooijen $\mathrm{N}$, Medvinsky A, et al. Role of host cell traversal by the malaria sporozoite during liver infection. J Exp Med. 2013;210(5):905-915.

18. Ashley EA, Pyae Phyo A, Woodrow CJ. Malaria. Lancet. 2018;391(10130):1608-1621.

19. Trampuz A, Jereb M, Muzlovic I, Prabhu RM. Clinical review: severe malaria. Crit Care. 2003;7(4):315-323.

20. Sypniewska P, Duda JF, Locatelli I, Althaus CR, Althaus F, Genton B. Clinical and laboratory predictors of death in African children with features of severe malaria: a systematic review and metaanalysis. BMC Med. 2017;15(1):147.

21. Luzolo AL, Ngoyi DM. Cerebral malaria. Brain Res Bull. 2019;145:53-58.

22. Josling GA, Llinas M. Sexual development in Plasmodium parasites: knowing when it's time to commit. Nat Rev Microbiol. 2015;13(9):573-587.

23. Brancucci NMB, Gerdt JP, Wang CQ, De Niz M, Philip N, Adapa SR, et al. Lysophosphatidylcholine regulates sexual stage differentiation in the human malaria parasite Plasmodium falciparum. Cell. 2017;171(7):1532.e1515-1544.e1515.

24. Anderios F, Noorrain A, Vythilingam I. In vivo study of human Plasmodium knowlesi in Macaca fascicularis. Exp Parasitol. 2010;124(2):181-189.

25. Collins WE, Jeffery GM. Plasmodium ovale: parasite and disease. Clin Microbiol Rev. 2005;18(3):570-581.

26. Galinski MR, Meyer EV, Barnwell JW. Plasmodium vivax: modern strategies to study a persistent parasite's life cycle. Adv Parasitol. 2013;81:1-26.

27. Mackerras MJ, Ercole QN. Observations on the life-cycle of Plasmodium malariae. Aust J Exp Biol Med Sci. 1948;26(Pt. 6): 515-519.

28. Su XZ, Mu J, Joy DA. The "Malaria's Eve" hypothesis and the debate concerning the origin of the human malaria parasite Plasmodium falciparum. Microbes Infect. 2003;5(10):891-896.

29. Loy DE, Liu W, Li Y, Learn GH, Plenderleith $L$, Sundararaman SA, et al. Out of Africa: origins and evolution of the human malaria parasites Plasmodium falciparum and Plasmodium vivax. Int J Parasitol. 2017;47(2-3):87-97.

30. Waters AP, Higgins DG, McCutchan TF. Plasmodium falciparum appears to have arisen as a result of lateral transfer between avian and human hosts. Proc Natl Acad Sci U S A. 1991;88(8):3140-3144.

31. Neafsey DE, Hartl DL, Berriman M. Evolution of noncoding and silent coding sites in the Plasmodium falciparum and Plasmodium reichenowi genomes. Mol Biol Evol. 2005;22(7):1621-1626.

32. Escalante AA, Ayala FJ. Phylogeny of the malarial genus Plasmodium, derived from rRNA gene sequences. Proc Natl Acad Sci U S A. 1994;91(24):11373-11377.

33. Sundararaman SA, Liu W, Keele BF, Learn GH, Bittinger $\mathrm{K}$, Mouacha F, et al. Plasmodium falciparum-like parasites infecting wild apes in southern Cameroon do not represent a recurrent source of human malaria. Proc Natl Acad Sci U S A. 2013;110(17):7020-7025.

34. Sharp PM, Plenderleith LJ, Hahn BH. Ape origins of human malaria. Annu Rev Microbiol. 2020;74:39-63.

35. Otto TD, Gilabert A, Crellen T, Bohme U, Arnathau C, Sanders $\mathrm{M}$, et al. Genomes of all known members of a Plasmodium subgenus reveal paths to virulent human malaria. Nat Microbiol. 2018;3(6):687-697.

36. Sundararaman SA, Plenderleith LJ, Liu W, Loy DE, Learn GH, Li $Y$, et al. Genomes of cryptic chimpanzee Plasmodium species reveal key evolutionary events leading to human malaria. Nat Commun. 2016;7:11078.

37. Su XZ, Zhang $C$, Joy DA. Host-malaria parasite interactions and impacts on mutual evolution. Front Cell Infect Microbiol. 2020;10:587933.
38. Sim BK, Chitnis CE, Wasniowska K, Hadley TJ, Miller LH. Receptor and ligand domains for invasion of erythrocytes by Plasmodium falciparum. Science. 1994;264(5167):1941-1944.

39. Martin MJ, Rayner JC, Gagneux P, Barnwell JW, Varki A. Evolution of human-chimpanzee differences in malaria susceptibility: relationship to human genetic loss of N-glycolylneuraminic acid. Proc Natl Acad Sci U S A. 2005;102(36):12819-12824.

40. Carvalho L, Oliveira SG, Alves FA, Brigido MC, Muniz JA, Daniel-Ribeiro CT. Aotus infulatus monkey is susceptible to Plasmodium falciparum infection and may constitute an alternative experimental model for malaria. Mem Inst Oswaldo Cruz. 2000;95(3):363-365.

41. Sa JM, Kaslow SR, Krause MA, Melendez-Muniz VA, Salzman RE, Kite WA, et al. Artemisinin resistance phenotypes and K13 inheritance in a Plasmodium falciparum cross and Aotus model. Proc Natl Acad Sci U S A. 2018;115(49):12513-12518.

42. Pye D, O'Brien CM, Franchina P, Monger C, Anders RF. Plasmodium falciparum infection of splenectomized and intact Guyanan Saimiri monkeys. J Parasitol. 1994;80(4):558-562.

43. Walliker D, Quakyi IA, Wellems TE, McCutchan TF, Szarfman A, London WT, et al. Genetic analysis of the human malaria parasite Plasmodium falciparum. Science. 1987;236(4809):1661-1666.

44. Wellems TE, Panton LJ, Gluzman IY, do Rosario VE, Gwadz RW, Walker-Jonah A, et al. Chloroquine resistance not linked to mdr-like genes in a Plasmodium falciparum cross. Nature. 1990;345(6272):253-255.

45. Wellems TE, Walliker D, Smith CL, do Rosario VE, Maloy WL, Howard RJ, et al. A histidine-rich protein gene marks a linkage group favored strongly in a genetic cross of Plasmodium falciparum. Cell. 1987;49(5):633-642.

46. Miller LH, Mason SJ, Clyde DF, McGinniss MH. The resistance factor to Plasmodium vivax in blacks. The Duffy-blood-group genotype, FyFy. N Engl J Med. 1976;295(6):302-304.

47. Escalante AA, Cornejo OE, Freeland DE, Poe AC, Durrego E, Collins WE, et al. A monkey's tale: the origin of Plasmodium vivax as a human malaria parasite. Proc Natl Acad Sci U S A. 2005;102(6):1980-1985.

48. Jongwutiwes S, Putaporntip C, Iwasaki T, Ferreira MU, Kanbara $\mathrm{H}$, Hughes AL. Mitochondrial genome sequences support ancient population expansion in Plasmodium vivax. Mol Biol Evol. 2005;22(8):1733-1739.

49. Mu J, Joy DA, Duan J, Huang Y, Carlton J, Walker J, et al. Host switch leads to emergence of Plasmodium vivax malaria in humans. Mol Biol Evol. 2005;22(8):1686-1693.

50. Neafsey DE, Galinsky K, Jiang RH, Young L, Sykes SM, Saif S, et al. The malaria parasite Plasmodium vivax exhibits greater genetic diversity than Plasmodium falciparum. Nat Genet. 2012;44(9):1046-1050.

51. Liu W, Li Y, Shaw KS, Learn GH, Plenderleith LJ, Malenke JA, et al. African origin of the malaria parasite Plasmodium vivax. Nat Commun. 2014;5:3346.

52. Arisue N, Hashimoto T, Kawai S, Honma H, Kume K, Horii T. Apicoplast phylogeny reveals the position of Plasmodium vivax basal to the Asian primate malaria parasite clade. Sci Rep. 2019;9(1):7274.

53. Daron J, Boissiere A, Boundenga L, Ngoubangoye B, Houze S, Arnathau C, et al. Population genomic evidence of Plasmodium vivax Southeast Asian origin. Sci Adv. 2021;7(18):eabc3713.

54. Carter R, Mendis KN. Evolutionary and historical aspects of the burden of malaria. Clin Microbiol Rev. 2002;15(4):564-594.

55. Carter R. Speculations on the origins of Plasmodium vivax malaria. Trends Parasitol. 2003;19(5):214-219.

56. Horuk R, Chitnis CE, Darbonne WC, Colby TJ, Rybicki A, Hadley TJ, et al. A receptor for the malarial parasite Plasmodium vivax: the erythrocyte chemokine receptor. Science. 1993;261(5125):1182-1184 
57. Chitnis CE, Miller LH. Identification of the erythrocyte binding domains of Plasmodium vivax and Plasmodium knowlesi proteins involved in erythrocyte invasion. J Exp Med. 1994;180(2):497-506.

58. Salinas ND, Tolia NH. Red cell receptors as access points for malaria infection. Curr Opin Hematol. 2016;23(3):215-223.

59. Livingstone FB. The Duffy blood groups, vivax malaria, and malaria selection in human populations: a review. Hum Biol. 1984;56(3):413-425.

60. Tournamille C, Colin Y, Cartron JP, Le Van Kim C. Disruption of a GATA motif in the Duffy gene promoter abolishes erythroid gene expression in Duffy-negative individuals. Nat Genet. 1995; 10(2):224-228

61. Zimmerman PA, Ferreira MU, Howes RE, Mercereau-Puijalon O. Red blood cell polymorphism and susceptibility to Plasmodium vivax. Adv Parasitol. 2013;81:27-76.

62. Menard D, Barnadas C, Bouchier C, Henry-Halldin C, Gray $\mathrm{LR}$, Ratsimbasoa $\mathrm{A}$, et al. Plasmodium vivax clinical malaria is commonly observed in Duffy-negative Malagasy people. Proc Natl Acad Sci U S A. 2010;107(13):5967-5971.

63. Golassa L, Amenga-Etego L, Lo E, Amambua-Ngwa A. The biology of unconventional invasion of Duffy-negative reticulocytes by Plasmodium vivax and its implication in malaria epidemiology and public health. Malar J. 2020;19(1):299.

64. Culleton R, Ndounga M, Zeyrek FY, Coban C, Casimiro PN, Takeo S, et al. Evidence for the transmission of Plasmodium vivax in the Republic of the Congo, West Central Africa. J Infect Dis. 2009;200(9):1465-1469.

65. Mendes C, Dias F, Figueiredo J, Mora VG, Cano J, de Sousa $B$, et al. Duffy negative antigen is no longer a barrier to Plasmodium vivax - molecular evidences from the African West Coast (Angola and Equatorial Guinea). PLoS Negl Trop Dis. 2011;5(6):e1192.

66. Ryan JR, Stoute JA, Amon J, Dunton RF, Mtalib R, Koros J, et al. Evidence for transmission of Plasmodium vivax among a duffy antigen negative population in Western Kenya. Am J Trop Med Hyg. 2006;75(4):575-581

67. Hostetler JB, Lo E, Kanjee U, Amaratunga C, Suon S, Sreng S, et al. Independent origin and global distribution of distinct Plasmodium vivax Duffy binding protein gene duplications. PLoS Negl Trop Dis. 2016;10(10):e0005091.

68. Menard D, Chan ER, Benedet C, Ratsimbasoa A, Kim S, Chim $P$, et al. Whole genome sequencing of field isolates reveals a common duplication of the Duffy binding protein gene in Malagasy Plasmodium vivax strains. PLoS Negl Trop Dis. 2013;7(11):e2489.

69. Pearson RD, Amato R, Auburn S, Miotto O, Almagro-Garcia J, Amaratunga C, et al. Genomic analysis of local variation and recent evolution in Plasmodium vivax. Nat Genet. 2016;48(8):959-964.

70. Popovici J, Roesch C, Carias LL, Khim N, Kim S, Vantaux A, et al. Amplification of Duffy binding protein-encoding gene allows Plasmodium vivax to evade host anti-DBP humoral immunity. Nat Commun. 2020;11(1):953.

71. Michon P, Woolley I, Wood EM, Kastens W, Zimmerman PA, Adams JH, et al. Duffy-null promoter heterozygosity reduces DARC expression and abrogates adhesion of the $P$. vivax ligand required for blood-stage infection. FEBS Lett. 2001;495(1-2):111-114.

72. Culleton RL, Ferreira PE. Duffy phenotype and Plasmodium vivax infections in humans and apes, Africa. Emerg Infect Dis. 2012;18(10):1704-1705.

73. Rayner JC, Liu W, Peeters M, Sharp PM, Hahn BH. A plethora of Plasmodium species in wild apes: a source of human infection? Trends Parasitol. 2011;27(5):222-229.

74. Lo E, Hostetler JB, Yewhalaw D, Pearson RD, Hamid MMA, Gunalan K, et al. Frequent expansion of Plasmodium vivax Duffy Binding Protein in Ethiopia and its epidemiological significance. PLoS Negl Trop Dis. 2019;13(9):e0007222.
75. Li J, Collins WE, Wirtz RA, Rathore D, Lal A, McCutchan TF. Geographic subdivision of the range of the malaria parasite Plasmodium vivax. Emerg Infect Dis. 2001;7(1):35-42.

76. Cormier LA. The historical ecology of human and wild primate malarias in the new world. Diversity. 2010;2(2):256-280.

77. Buery JC, Rodrigues PT, Natal L, Salla LC, Loss AC, Vicente $C R$, et al. Mitochondrial genome of Plasmodium vivax/simium detected in an endemic region for malaria in the Atlantic Forest of Espirito Santo state, Brazil: do mosquitoes, simians and humans harbour the same parasite? Malar J. 2017;16(1):437.

78. de Oliveira TC, Rodrigues PT, Early AM, Duarte A, Buery JC, Bueno MG, et al. Plasmodium simium: population genomics reveals the origin of a reverse zoonosis. J Infect Dis. 2021:jiab214.

79. Mourier T, de Alvarenga DAM, Kaushik A, de Pina-Costa A, Douvropoulou O, Guan Q, et al. The genome of the zoonotic malaria parasite Plasmodium simium reveals adaptations to host switching. BMC Biol. 2021;19:219.

80. Brasil P, Zalis MG, de Pina-Costa A, Siqueira AM, Junior $C B$, Silva $S$, et al. Outbreak of human malaria caused by Plasmodium simium in the Atlantic Forest in Rio de Janeiro: a molecular epidemiological investigation. Lancet Glob Health. 2017;5(10):e1038-e1046.

81. Stephens JWW. A new malaria parasite of man. Ann Trop Med Parasitol. 1922;16:383-388.

82. Alves W, Schinazi LA, Aniceto F. Plasmodium ovale infections in the Philippines. Bull World Health Organ. 1968;39(3):494-495.

83. Costescu Strachinaru DI, Wauters A, van Esbroeck M, Strachinaru M, Vanbrabant P, Soentjens P. A Cluster of Plasmodium ovale infections in Belgian military personnel after deployment in Kindu, Democratic Republic of Congo: a retrospective study. Trop Med Infect Dis. 2021;6(3):125.

84. Quaye IK, Aleksenko L, Oeuvray C, Yewhalaw D, Duah N, Gyan B, et al. The Pan African Vivax and Ovale Network (PAVON): refocusing on Plasmodium vivax, ovale and asymptomatic malaria in sub-Saharan Africa. Parasitol Int. 2021;84:102415.

85. Lysenko AJ, Beljaev AE. An analysis of the geographical distribution of Plasmodium ovale. Bull World Health Organ. 1969;40(3):383-394.

86. Cadigan FC, Desowitz RS. Two cases of Plasmodium ovale malaria from central Thailand. Trans R Soc Trop Med Hyg. 1969;63(5):681-682.

87. Incardona S, Chy S, Chiv L, Nhem S, Sem R, Hewitt S, et al. Large sequence heterogeneity of the small subunit ribosomal RNA gene of Plasmodium ovale in cambodia. Am J Trop Med Hyg. 2005;72(6):719-724.

88. Gleason NN, Fisher GU, Blumhardt R, Roth AE, Gaffney GW. Plasmodium ovale malaria acquired in Viet-Nam. Bull World Health Organ. 1970;42(3):399-403.

89. Snounou G, Viriyakosol S, Jarra W, Thaithong S, Brown KN. Identification of the four human malaria parasite species in field samples by the polymerase chain reaction and detection of a high prevalence of mixed infections. Mol Biochem Parasitol. 1993;58(2):283-292.

90. Duval L, Nerrienet E, Rousset D, Sadeuh Mba SA, Houze S, Fourment $\mathrm{M}$, et al. Chimpanzee malaria parasites related to Plasmodium ovale in Africa. PLoS One. 2009;4(5):e5520.

91. Su XZ. Human malaria parasites: are we ready for a new species? J Infect Dis. 2010;201(10):1453-1454.

92. Sutherland CJ, Tanomsing N, Nolder D, Oguike M, Jennison C, Pukrittayakamee $S$, et al. Two nonrecombining sympatric forms of the human malaria parasite Plasmodium ovale occur globally. J Infect Dis. 2010;201(10):1544-1550.

93. Rutledge GG, Bohme U, Sanders M, Reid AJ, Cotton JA, Maiga-Ascofare $\mathrm{O}$, et al. Plasmodium malariae and P. ovale genomes provide insights into malaria parasite evolution. Nature. 2017;542(7639):101-104.

94. Duval L, Fourment M, Nerrienet E, Rousset D, Sadeuh SA, Goodman SM, et al. African apes as reservoirs of Plasmodium falciparum and the origin and diversification 
of the Laverania subgenus. Proc Natl Acad Sci U S A. 2010;107(23):10561-10566.

95. Kaiser M, Lowa A, Ulrich M, Ellerbrok H, Goffe AS, Blasse A, et al. Wild chimpanzees infected with 5 Plasmodium species. Emerg Infect Dis. 2010;16(12):1956-1959.

96. Coatney GR, Collins WE, Warren M, Contacos PG. CD-ROM. The primate malarias: [Original book published 1971]. Division of Parasitic Disease, Producers. Version 1.0. CDC, Atlanta, GA; 2003

97. Bray RS. Studies on malaria in chimpanzees. VIII. The experimental transmission and pre-erythrocytic phase of Plasmodium malariae, with a note on the host-range of the parasite. Am J Trop Med Hyg. 1960;9:455-465.

98. Geiman QM, Siddiqui WA. Susceptibility of a New World monkey to Plasmodium malariae from aman. Am J Trop Med Hyg. 1969;18(3):351-354.

99. Contacos PG, Lunn JS, Coatney GR, Kilpatrick JW, Jones FE. Quartan-type malaria parasite of new world monkeys transmissible to man. Science. 1963;142(3593):676.

100. Fandeur T, Volney B, Peneau C, de Thoisy B. Monkeys of the rainforest in French Guiana are natural reservoirs for P. brasilianum/P. malariae malaria. Parasitology. 2000; 120(Pt 1):11-21.

101. Lalremruata A, Magris M, Vivas-Martinez S, Koehler M, Esen M, Kempaiah P, et al. Natural infection of Plasmodium brasilianum in humans: man and monkey share quartan malaria parasites in the Venezuelan Amazon. EBioMedicine. 2015;2(9):1186-1192.

102. Guimaraes LO, Bajay MM, Wunderlich G, Bueno MG, Rohe F, Catão-Dias JL, et al. The genetic diversity of Plasmodium malariae and Plasmodium brasilianum from human, simian and mosquito hosts in Brazil. Acta Trop. 2012;124(1):27-32.

103. Knowles R, Gupta BMD. A study of monkey-malaria, and its experimental transmission to man. Ind Med Gaz. 1932;67(6):301-320.

104. Singh B, Daneshvar C. Human infections and detection of Plasmodium knowlesi. Clin Microbiol Rev. 2013;26(2):165-184.

105. Chin W, Contacos PG, Coatney GR, Kimball HR. A naturally acquited quotidian-type malaria in man transferable to monkeys. Science. 1965;149(3686):865.

106. Ramasamy R. Zoonotic malaria - global overview and research and policy needs. Front Public Health. 2014;2:123.

107. Singh B, Kim Sung L, Matusop A, Radhakrishnan A, Shamsul SS, Cox-Singh J, et al. A large focus of naturally acquired Plasmodium knowlesi infections in human beings. Lancet. 2004;363(9414):1017-1024.

108. Siner A, Liew ST, Kadir KA, Mohamad DSA, Thomas FK, Zulkarnaen $\mathrm{M}$, et al. Absence of Plasmodium inui and Plasmodium cynomolgi, but detection of Plasmodium knowlesi and Plasmodium vivax infections in asymptomatic humans in the Betong division of Sarawak, Malaysian Borneo. Malar J. 2017; 16(1):417

109. Vythilingam I, Noorazian YM, Huat TC, Jiram Al, Yusri YM, Azahari $\mathrm{AH}$, et al. Plasmodium knowlesi in humans, macaques and mosquitoes in peninsular Malaysia. Parasit Vectors. 2008; $1(1): 26$.

110. Grignard L, Shah S, Chua TH, William T, Drakeley CJ, Fornace KM. Natural human infections with Plasmodium cynomolgi and other malaria species in an elimination setting in Sabah, Malaysia. J Infect Dis. 2019;220(12):1946-1949.

111. Raja TN, Hu TH, Kadir KA, Mohamad DSA, Rosli N, Wong LL, et al. Naturally acquired human Plasmodium cynomolgi and P. Knowlesi infections, Malaysian Borneo. Emerg Infect Dis. 2020;26(8):1801-1809.

112. Jongwutiwes $S$, Putaporntip $C$, Iwasaki T, Sata T, Kanbara $H$. Naturally acquired Plasmodium knowlesi malaria in human, Thailand. Emerg Infect Dis. 2004;10(12):2211-2213.

113. Jongwutiwes $S$, Buppan P, Kosuvin R, Seethamchai $S$, Pattanawong U, Sirichaisinthop J, et al. Plasmodium knowlesi
Malaria in humans and macaques, Thailand. Emerg Infect Dis. 2011;17(10):1799-1806.

114. Putaporntip C, Hongsrimuang $T$, Seethamchai S, Kobasa T, Limkittikul K, Cui L, et al. Differential prevalence of Plasmodium infections and cryptic Plasmodium knowlesi malaria in humans in Thailand. J Infect Dis. 2009;199(8):1143-1150.

115. Khim N, Siv S, Kim S, Mueller T, Fleischmann E, Singh B, et al. Plasmodium knowlesi infection in humans, Cambodia, 2007-2010. Emerg Infect Dis. 2011;17(10):1900-1902.

116. Imwong M, Madmanee W, Suwannasin K, Kunasol C, Peto TJ, Tripura R, et al. Asymptomatic natural human infections with the simian malaria parasites Plasmodium cynomolgi and Plasmodium knowlesi. J Infect Dis. 2019;219(5):695-702.

117. van den Eede $P$, van $H N$, van Overmeir C, Vythilingam I, Duc TN, Hung $X$, et al. Human Plasmodium knowlesi infections in young children in central Vietnam. Malar J. 2009;8:249.

118. Jiang N, Chang Q, Sun X, Lu H, Yin J, Zhang Z, et al. Co-infections with Plasmodium knowlesi and other malaria parasites, Myanmar. Emerg Infect Dis. 2010;16(9):1476-1478.

119. Luchavez J, Espino F, Curameng P, Espina R, Bell D, Chiodini $P$, et al. Human infections with Plasmodium knowlesi, the Philippines. Emerg Infect Dis. 2008;14(5):811-813.

120. $\mathrm{Ng} \mathrm{OT,} \mathrm{Ooi} \mathrm{EE,} \mathrm{Lee} \mathrm{CC,} \mathrm{Lee} \mathrm{PJ,} \mathrm{Ng} \mathrm{LC,} \mathrm{Pei} \mathrm{SW,} \mathrm{et} \mathrm{al.} \mathrm{Naturally}$ acquired human Plasmodium knowlesi infection, Singapore. Emerg Infect Dis. 2008;14(5):814-816.

121. Jeslyn WP, Huat TC, Vernon L, Irene LM, Sung LK, Jarrod LP, et al. Molecular epidemiological investigation of Plasmodium knowlesi in humans and macaques in Singapore. Vector Borne Zoonotic Dis. 2011;11(2):131-135.

122. Figtree M, Lee R, Bain L, Kennedy T, Mackertich S, Urban M, et al. Plasmodium knowlesi in human, Indonesian Borneo. Emerg Infect Dis. 2010;16(4):672-674.

123. Naik DG. Plasmodium knowlesi-mediated zoonotic malaria: a challenge for elimination. Trop Parasitol. 2020;10(1):3-6.

124. Lai MY, Rafieqin N, Lee PYL, Amir Rawa MS, Dzul S, Yahaya $\mathrm{N}$, et al. High incidence of Plasmodium knowlesi malaria compared to other human malaria species in several hospitals in Malaysia. Trop Biomed. 2021;38(3):248-253.

125. Collins WE. Primate malarias. Adv Vet Sci Comp Med. 1974;18(0):1-23.

126. Kotepui M, Masangkay FR, Kotepui KU, Milanez GJ. Preliminary review on the prevalence, proportion, geographical distribution, and characteristics of naturally acquired Plasmodium cynomolgi infection in mosquitoes, macaques, and humans: a systematic review and meta-analysis. BMC Infect Dis. 2021;21(1):259.

127. Eyles DE, Coatney GR, Getz ME. Vivax-type malaria parasite of macaques transmissible to man. Science. 1960;131(3416):1812-1813.

128. Coatney GR, Elder HA, Contacos PG, Getz ME, Greenland $R$, Rossan RN, et al. Transmission of the M strain of Plasmodium cynomolgi to man. Am J Trop Med Hyg. 1961;10:673-678.

129. Bennett GF, Warren M. Transmission of a new strain of Plasmodium Cynomolgi to man. J Parasitol. 1965;51:79-80.

130. Schmidt LH, Greenland R, Genther CS. The transmission of Plasmodium cynomolgi to man. Am J Trop Med Hyg. 1961;10:679-688.

131. Contacos PG, Elder HA, Coatney GR, Genther C. Man to man transfer of two strains of Plasmodium cynomolgi by mosquito bite. Am J Trop Med Hyg. 1962;11:186-193.

132. Ta TH, Hisam S, Lanza M, Jiram Al, Ismail N, Rubio JM. First case of a naturally acquired human infection with Plasmodium cynomolgi. Malar J. 2014;13:68.

133. Valkiunas $G$, lezhova TA. Keys to the avian malaria parasites. Malar J. 2018;17(1):212.

134. Santiago-Alarcon D, Palinauskas V, Schaefer HM. Diptera vectors of avian Haemosporidian parasites: untangling parasite 
life cycles and their taxonomy. Biol Rev Camb Philos Soc. 2012;87(4):928-964.

135. Njabo KY, Cornel AJ, Sehgal RN, Loiseau C, Buermann W, Harrigan RJ, et al. Coquillettidia (Culicidae, Diptera) mosquitoes are natural vectors of avian malaria in Africa. Malar J. 2009;8:193.

136. Yuda P. Detection of avian malaria in wild birds at Trisik Beach of Yogyakarta, Java (Indonesia). Ann Parasitol. 2019;65(2):171-175.

137. Ilgunas M, Bukauskaite D, Palinauskas V, lezhova TA, Dinhopl $\mathrm{N}$, Nedorost N, et al. Mortality and pathology in birds due to Plasmodium (Giovannolaia) homocircumflexum infection, with emphasis on the exoerythrocytic development of avian malaria parasites. Malar J. 2016;15(1):256.

138. Niebuhr CN, Poulin R, Tompkins DM. Is avian malaria playing a role in native bird declines in New Zealand? Testing hypotheses along an elevational gradient. PLoS One. 2016;11(11):e0165918.

139. Dadam D, Robinson RA, Clements A, Peach WJ, Bennett $\mathrm{M}$, Rowcliffe JM, et al. Avian malaria-mediated population decline of a widespread iconic bird species. R Soc Open Sci. 2019;6(7):182197.

140. Williams RB. Avian malaria: clinical and chemical pathology of Plasmodium gallinaceum in the domesticated fowl Gallus gallus. Avian Pathol. 2005;34(1):29-47.

141. Grilo ML, Vanstreels RE, Wallace R, Garcia-Parraga D, Braga EM, Chitty J, et al. Malaria in penguins - current perceptions. Avian Pathol. 2016;45(4):393-407.

142. Levin II, Zwiers P, Deem SL, Geest EA, Higashiguchi JM, lezhova TA, et al. Multiple lineages of Avian malaria parasites (Plasmodium) in the Galapagos Islands and evidence for arrival via migratory birds. Conserv Biol. 2013;27(6):1366-1377.

143. Theodosopoulos AN, Grabenstein KC, Bensch S, Taylor SA. A highly invasive malaria parasite has expanded its range to nonmigratory birds in North America. Biol Lett. 2021;17(9):20210271.

144. Jia T, Huang $X$, Valkiunas $G$, Yang M, Zheng C, Pu T, et al. Malaria parasites and related haemosporidians cause mortality in cranes: a study on the parasites diversity, prevalence and distribution in Beijing Zoo. Malar J. 2018;17(1):234.

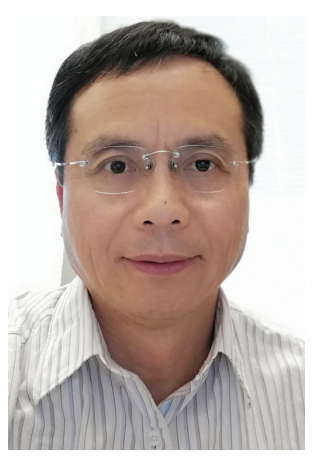

Dr. Su received his B.S. degree in Biology and Parasitology in 1982 and M.S. degree in 1985 from Xiamen University, China. He obtained his Ph.D. in parasitology from the University of Georgia in 1990. He joined the Laboratory of Parasitic Diseases, National Institutes of Health USA, as a Staff Fellow in 1992 and became a tenure-track investigator in the Laboratory of Malaria and Vector Research in 2001. He has been a tenured senior investigator studying malaria genetics, genomics, molecular evolution, drug resistance, and host-parasite interaction since 2006. 